\title{
COEFFICIENT OF DISCHARGE OF CHIMNEY WEIR UNDER FREE AND SUBMERGED FLOW CONDITIONS
}

\author{
Hanaa A .M.Hayawi \\ Ghania A.M.Hayawi \\ College Of Engineering - University Of Mosul
}

\begin{abstract}
:
The main objective of this investigation is to study experimentally the water surface profiles and to obtain convenient expressions for the estimation of discharge coefficients $\left(\mathrm{C}_{\mathrm{d}}\right)$ for free flow over chimney weir and the discharge factor $\left(\mathrm{q} / \mathrm{q}_{1}\right)$ for submerged flow. Four chimney weir models with different vertex angles were constructed and tested, the surface water profiles, for all models were smooth upstream and fall suddenly downstream the model and at a high discharge it become concave while at law discharge the water surface profile become convex. The coefficient of discharge for free flow increase with the decrease of the upstream head and with the decrease of half vertex angle $(\theta)$. While the discharge factor for submerged flow increase with the decrease of the submergence ratio $\left(\mathrm{h}_{2} / \mathrm{h}_{1}\right)$. Two general expressions were optioned, one, for the estimation of $\mathrm{C}_{\mathrm{d}}$ with respect of $(\mathrm{h} / \mathrm{p}),(\mathrm{w} / \mathrm{p})$ and $\theta$ for free flow conditions and the other for estimation of the coefficient factor $\left(\mathrm{q} / \mathrm{q}_{1}\right)$ with respect to $\left(\mathrm{h}_{2} / \mathrm{h}_{1}\right)$ and $\left(\mathrm{h}_{1} / \mathrm{p}\right)$.
\end{abstract}

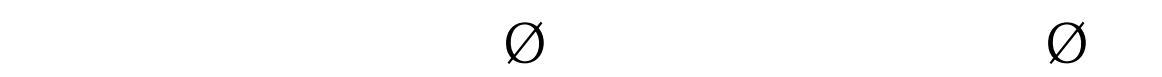 tớdigtzšnE}

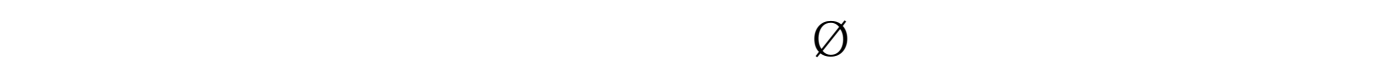

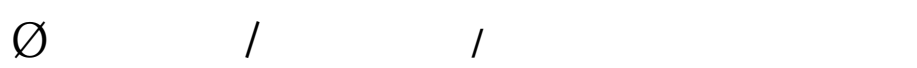

\section{rU゚' ŤKE}

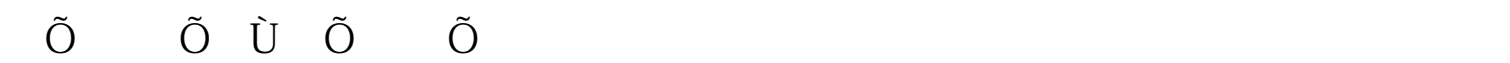

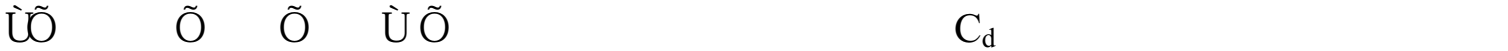

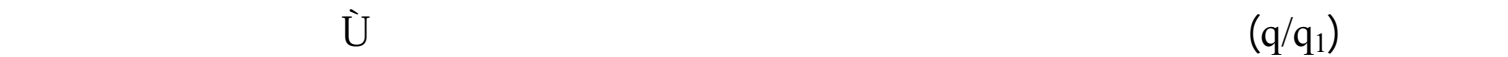

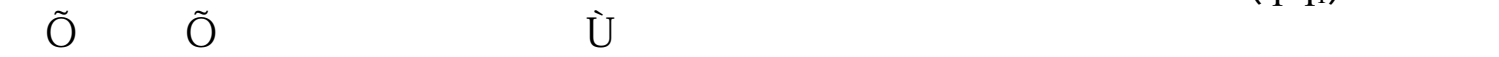

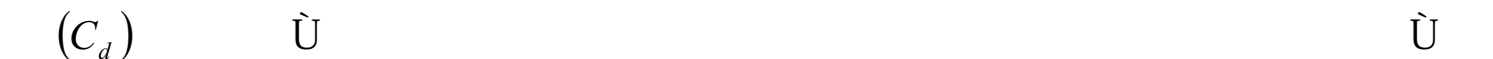

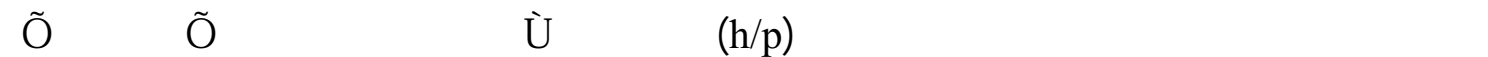

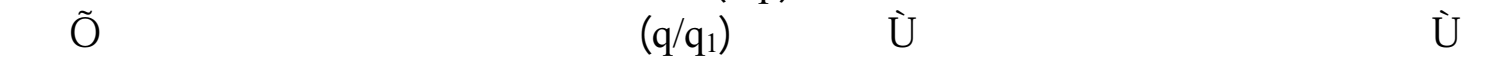

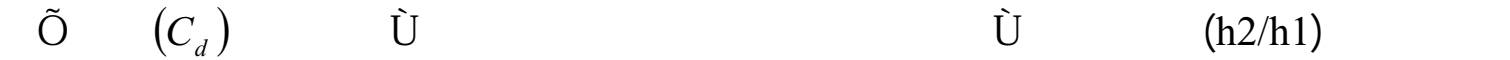

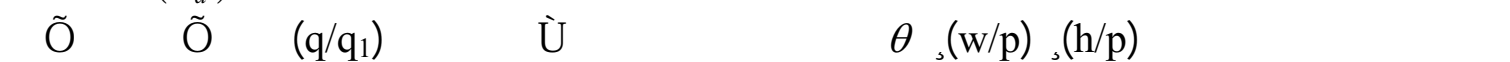
.$\left(\mathrm{h}_{1} / \mathrm{p}\right) \partial\left(\mathrm{h}_{2} / \mathrm{h}_{1}\right)$ r 


\section{Introduction}

The V-shaped broad-crested weir is a measuring structure whose characteristics meet modern demands of water resources development, particularly in irrigation and hydrologic studies. It amply meets requirements in terms of measuring range and accuracy.

The V-shaped broad-crested weir can be constructed either with a fixed crest or movable crest (Wubbo Boiten et al. 1982). The maximum discharge depends on the chosen dimensions. The weir is a suitable measuring device for small and moderate discharges, recently, a few practical linear weirs have been proposed that offer the advantage of simple geometry and a sufficiently high degree of accuracy

The quadrant plate weir (Ramamurty et.al 1977), the inverted V-notch (IVN) (Keshava Murthy and Girdhar 1989), the chimney weir (Keshava Murthy and Girdhar. 1991) and the modified EBM weir (Keshava Murthy,K., et. al 1994). The inverted V-notch and the chimney weir are the simplest of the lot as they are formed by straight lines only.

The chimney weir, an improvement over the inverted V-notch, is formed by the addition of a rectangular section to the top of an inverted $\mathrm{V}$-notch. This results in a considerably enhanced measuring range over that of an inverted $V$-notch. However, to make it useful as a measuring device in open channels where head cannot be sacrificed, detailed studies on submergence characteristics of chimney weir are necessary. Experiments are conducted by (Chatterjee et. at 1998) to evaluate the accuracy of the theoretical equation (1) as shown.

$$
C_{d}=0.5+0.094\left(\frac{h_{1}}{p}\right)-0.028\left(\frac{h_{1}}{p}\right)^{2}
$$

$\mathrm{r}^{2}=0.625$

Where: -

$C_{d}=$ Coefficient of discharge for linear head- discharge relationship.

$h_{1}=$ Upstream head above weir crest for submerge flow.

$\mathrm{P}=$ Height of trapezium.

A comparison of eq. (1) with the submergence formulas for sharp crested weir developed by (Vilemonte 1947) and (Mavis 1949) had done.

In the present investigation, more information was presented on the characteristics of free and submerged flow conditions over chimney weirs. The experimental results were presented to validate a general expression for the estimation of discharge coefficient in terms of relative upstream head over weir crest for free flow condition and in terms of upstream and downstream head above crest weir for submerged flow conditions and a longitudinal water surface profiles were recorded and examined carefully upstream and downstream the weir crest for free flow condition.

\section{Experimental Set Up}

The experiments were carried out in a horizontal channel of working length of $(10 \mathrm{~m})$, with a cross section $(0.3 \mathrm{~m})$ wide and $(0.45 \mathrm{~m})$ high. Fig. (1) shows the details of the channel. Two movable carriage equipped with point gauges were mounted on the rails. 
Four chimney weirs models with different vertex angle were manufactured from a large sheet of thin wood plate $(2 \mathrm{~mm})$ thickness, the edge of each weir model were shown in Fig. (2) and table (1).

Table (1) Details of the chimney weir tested

\begin{tabular}{|c|c|c|c|}
\hline Run No. & $\theta^{\circ}$ & $\mathrm{P}(\mathrm{cm})$ & $\mathrm{W}(\mathrm{cm})$ \\
\hline $1-7$ & 15 & 10.8 & 4 \\
\hline $8-13$ & 26 & 12.5 & 7 \\
\hline $14-20$ & 34 & 13.3 & 10 \\
\hline $21-26$ & 41 & 13.7 & 13 \\
\hline
\end{tabular}

All weir models were fixed at a distance of $1.5 \mathrm{~m}$ upstream from the channel outlet section and the discharges were measured with a standard full width thin plate sharpcrested rectangular weir of $15 \mathrm{~cm}$ height located downstream the channel section. This standard weir was manufactured according to British standard (British Standard Institution 1965).

The water surface profile were recorded for each test and the discharge over the model were measured with the standard weir, the head upstream the standard weir and chimney weir for free flow were measured with a precision point gauges whose least count was $0.1 \mathrm{~mm}$ and the upstream and downstream head over the submerged chimney weir are also measured with a point gauges having at least count of $0.1 \mathrm{~mm}$ placed 1.4 and $4.5 \mathrm{~m}$ upstream and downstream of the weir respectively.

A gate downstream end of the channel is used to control the degree of submergence.

\section{Analysis of Results}

\section{Water Surface Profiles}

The experimental results of the measurements of water surface profiles along the centerline of

the model (at $15 \mathrm{~cm}$ from the channel edge) and at $7.5 \mathrm{~cm}$ from the channel edge show a descending trend from the point of measurement to the entrance section of the model. This trend continues in the direction of flow along the weir with a steep drop near the downstream face of the chimney weir Fig. (3 and 4) shows a plot of the water surface profiles of $\mathrm{Y}$ versus $\mathrm{X}$ for all tests of chimney model of $\theta=41^{\circ}$ at 15 and $7.5 \mathrm{~cm}$ from the channel where, $\mathrm{Y}$ is the depth of flow recorded above the crest and $\mathrm{X}$ is the horizontal distance measured from the crest also Fig. (3 and 4) show the water surface profile convex at low discharge and concave at high discharge.

\section{A- $\quad$ Free Flow Conditions}

\section{Variation of Cd With h/p:}

The coefficient of discharge is calculated from equations (3 and 4) (C.Chatterjee.1998) for $0 \leq h \leq p$ and $\mathrm{h} \geq p$ respectively. Fig. (5) shows a plot of the coefficient of discharge $\mathrm{Cd}$ versus the ratio of the upstream head and crest height $(\mathrm{h} / \mathrm{p})$ for each of chimney weir tested .From Fig.(5) the coefficient of discharge Cd decrease with the increase of $\theta$ and $\mathrm{P}$ for a constant value of $(\mathrm{h} / \mathrm{p})$ and $\mathrm{Cd}$ increase with the decrease of $\mathrm{h} / \mathrm{p}$, this can be attributed to the nape interference of the falling flow downstream the crest near the walls. 
Regression analysis is performed to correlate the coefficient of discharge $\mathrm{Cd}, \mathrm{h} / \mathrm{p}, \mathrm{w} / \mathrm{p}$ and $\theta$ values, the equation of the following formed is found to be the best:-

$$
C d=\frac{0.748 \theta^{0.318}}{\left(\frac{h}{p}\right)^{0.038}\left(\frac{w}{p}\right)^{0.575}}
$$

$\mathrm{r}^{2}=0.87$

Where:-

$\theta=$ half vertex angle in radian.

$\mathrm{h}=$ head above weir crest for free flow.

$\mathrm{P}=$ height of a trapezium.

$\mathrm{W}=$ half crest width

\section{B- Submerged flow conditions}

Variation of $q / q_{1}$ with $h_{2} / h_{1}$ :

The discharge factor $\mathrm{q} / \mathrm{q} 1$ is calculated using Villemonte formula for chimney weir:

$$
\frac{q}{q_{1}}=k\left(1-\frac{h_{2}}{h_{1}}\right)^{m}
$$

Where:-

$\mathrm{q}=$ discharge

$\mathrm{q}_{1}=$ free-flow discharge due to upstream head $\mathrm{h}_{1}$.

$\mathrm{h}_{2}=$ downstream head above weir crest.

$\mathrm{k}, \mathrm{m}=$ coefficients of Villemonte formula equal 1.043 and 0.396 respectively.

Fig.(6) shows a plot of discharge factor $q / q 1$, versus the submergence ratio $h_{2} / h_{1}$ it is observed that at a low submergence ratio, the discharge factor is high, this is because at law submergence ratio the pressure beneath the nape is lower than the corresponding fully aerated napes which cause a greater pressure difference across the weir, hence produces a larger discharge for the same head $\mathrm{h}_{1}$ and a multiple regression analysis is performed to correlate the $\mathrm{q} / \mathrm{q}_{1}, \mathrm{~h}_{2} / \mathrm{h}_{1}$ and $\mathrm{h}_{1} / \mathrm{p}$ values, the following equation is found to be the best fit:-

$$
\frac{q}{q_{1}}=0.989-0.0957\left(\frac{h_{2}}{h_{1}}\right)-0.569\left(\frac{h_{2}}{h_{1}}\right)^{2}-0.076\left(\frac{h_{1}}{p}\right)
$$

$\mathrm{r}^{2}=0.9987$

\section{Conclusions}

From the experimental results of this study the following conclusions can be drawn:1- The water surface profiles for all the chimney weirs were smooth and continuous upstream the chimney weir at the center line of the channel, and drop suddenly downstream. Also the water surface profile becomes concave as the discharge increase and convex as the discharge decrease.

2- The coefficient of the discharge $\left(\mathrm{C}_{\mathrm{d})}\right.$ increases with the increase of the upstream head $(\mathrm{h} / \mathrm{p})$ and with decrease of half vertex angle $(\theta)$ for free flow conditions. 
3- The discharge factor $\left(\mathrm{q} / \mathrm{q}_{1}\right)$ increases with the decrease of the submergence ratio $\left(\mathrm{h}_{2} / \mathrm{h}_{1}\right)$ for submerged flow conditions.

4- Two general expressions were obtained one for estimation of $\left(C_{d}\right)$ with respect to upstream head $(\mathrm{h} / \mathrm{p})$, the half crest width of the chimney weir (w)and the half vertex angle $(\theta)$ for free flow conditions and the other for estimation of the discharge factor $\left(\mathrm{q} / \mathrm{q}_{1}\right)$ with the submergence ratio $\left(\mathrm{h}_{2} / \mathrm{h}_{1}\right)$ and $(\mathrm{h} 1 / \mathrm{p})$ values for submerged flow conditions.

\section{Notations}

$\mathrm{C}_{\mathrm{d}}=$ coefficient of discharge

$\mathrm{d}=$ altitude of inverted $\mathrm{V}$ - notch

$\mathrm{g}=$ acceleration due to gravity

$\mathrm{h}_{1}=$ upstream head above weir crest for submerged flow

$\mathrm{h}_{2}=$ downstream head above weir crest

$\mathrm{h}=$ head above weir crest for free flow

$\mathrm{k}, \mathrm{m}=$ constants

$\mathrm{p}=$ height of trapezium

$\mathrm{q}=$ discharge

$\mathrm{q}_{1}=$ free flow discharge due to upstream head $\mathrm{h}_{1}$

$\mathrm{t}=$ half width of rectangular portion

$\mathrm{w}=$ half crest width

$\theta=$ half vertex angle

\section{Reference}

1- British Standard Institution.(1965) "Methods of Measurement of Liquid Flow in Open Channels". London. England.Bs.3680.(part 4A).

2- C.Chatterjee,et al.(1998)"Flow Characteristics of Chimney Weir Under Submergence" Journal of Irr. And Drainage Eng.March/April.

3- Keshava Murthy, K.,and Girdhar,D.P.(1989).”Inverted V-notch; A Practical Proportional Weir "J.Irrg. and Drain. Eng., ASCE. 115(6), 1035-1050.

4- K eshava Murthy, K., and Girdhar,D.P.(991)."Geometrically Simple Linear Weirs Using Circular Quadrants -Bell Mouth Weirs." J.Hydr.Res. 29(4), 497-509.

5- Keshava MurthY ,K., and Shesha Prakash,M.N.(1994).”Practical Constant- Accuracy linear Weir.”J.Irr. and Drain Eng., ASCE, 120(3), 550-562.

6- Mavis,F.T.(1949)"How to Calculate Flow Over Submerged Thin Plate Weirs,"Eng.News Record,143(1),65-69.

7- Ramamurty, A.S., Subramanya,K.,and Pani. B.S., (1977),"Quadrant Plate Weir" J. Hydr. Div.ASCE, 103(2), 1431-1441.

8- Villemoute ,J.R (1947). "Submerged Weir Discharges studies” Eng. New Record.139 (26), 866-869.

9-Wubbo Boiten and Remmet H.Pitlo.,(1982)"The V-Shape Board-Crested Weir" Journal of the Irrigation and Drainage Division Vol.108 No. 1R2. JUNE. 


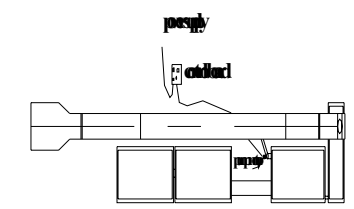

Buriding

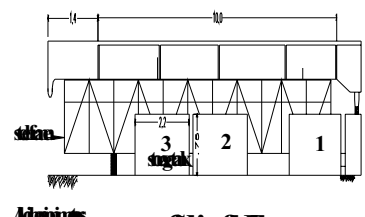

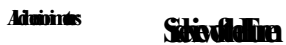

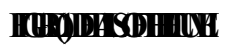

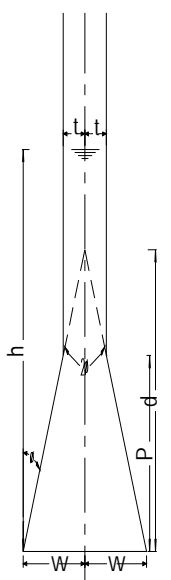

C.

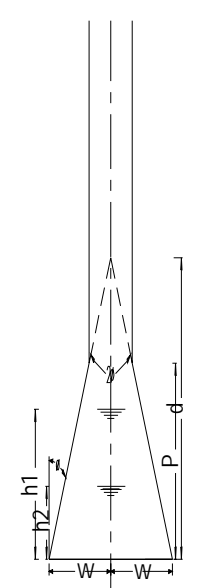

C

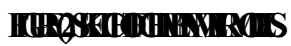



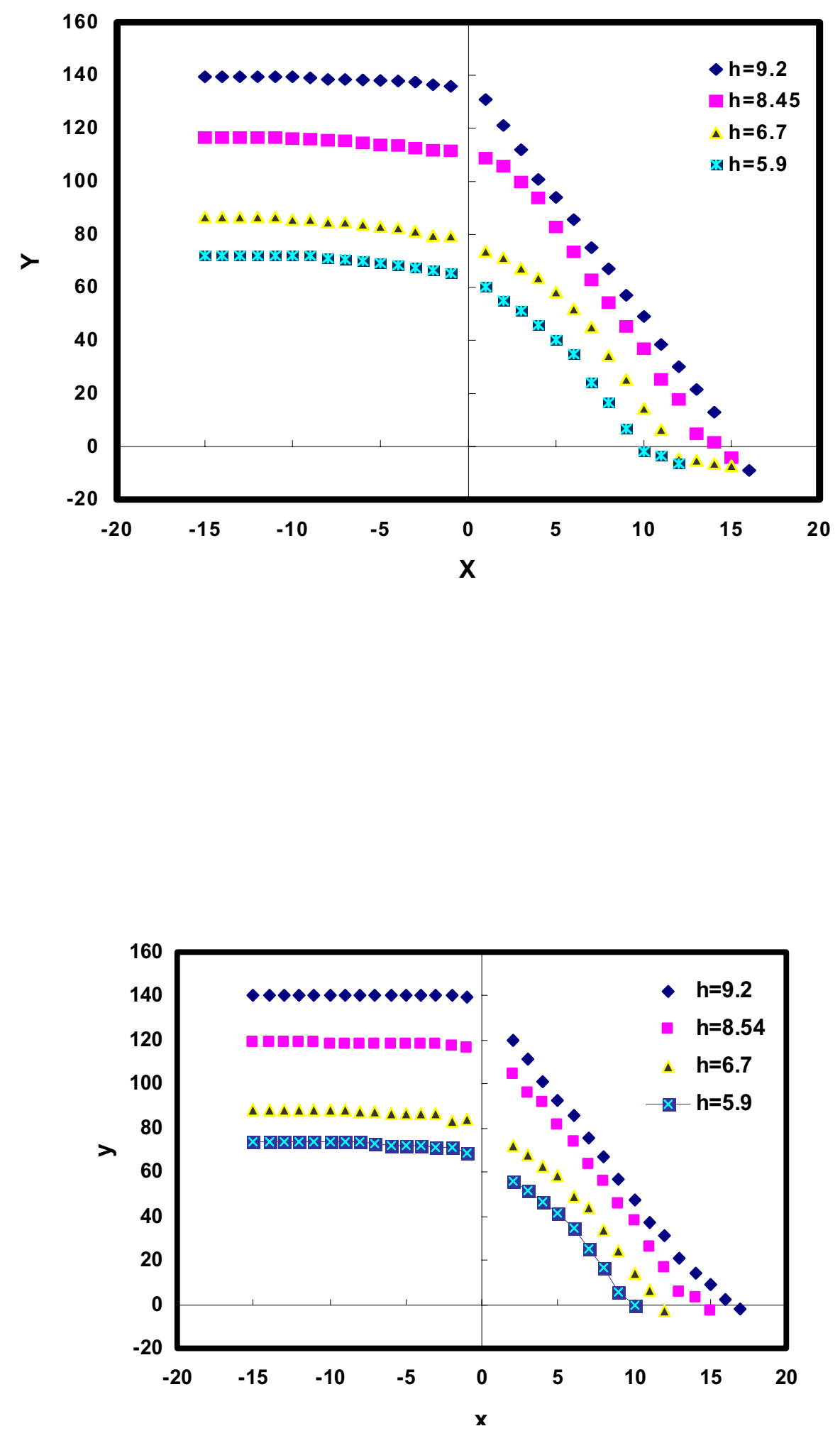

Fig.(4) Water Surface Profile at $7.5 \mathrm{~cm}$ from the channel edge, for model $\theta=41$ 


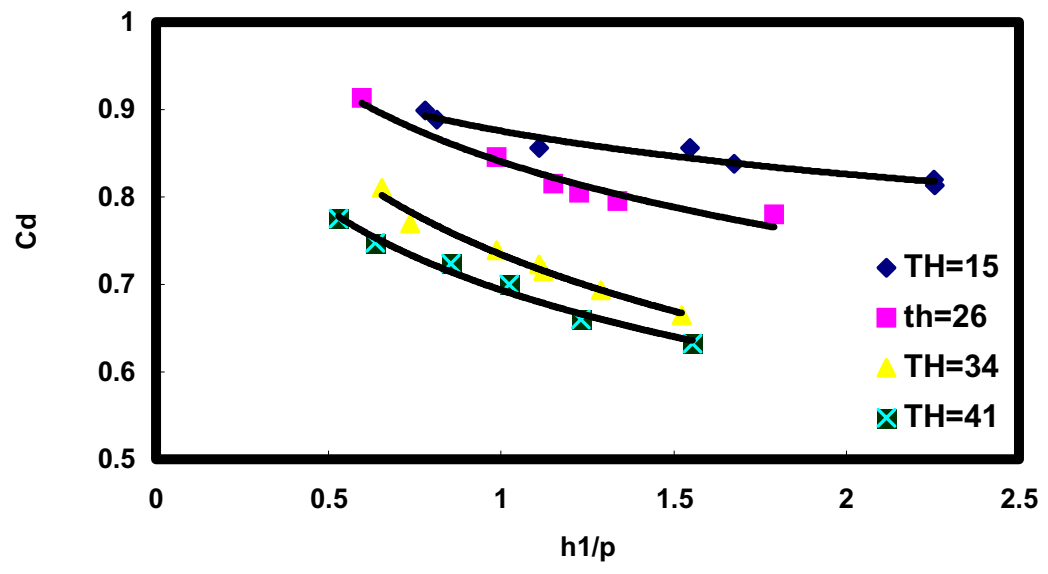

Fig..(5) Relation Between Coefficient Of Discharge Cd With (h1/p) For Free Condition.

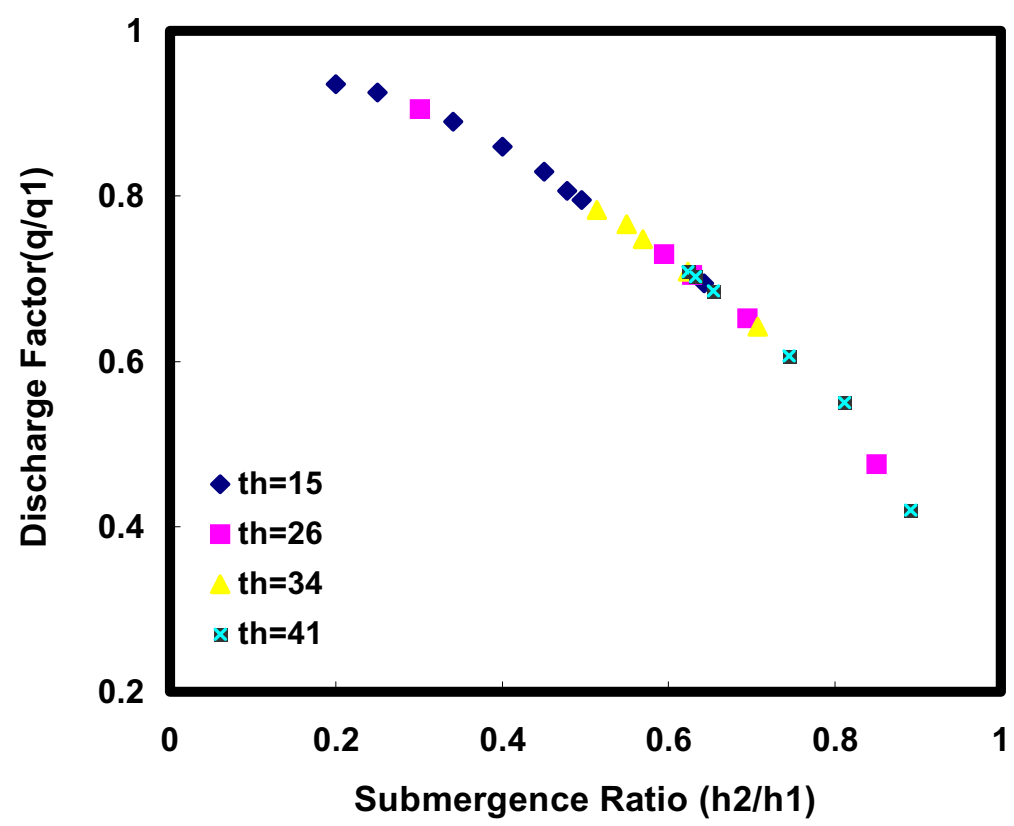

Fig.(6) Variation Of Discharge Factor With Submergence Ratio 